\title{
FASILITAS KESEHATAN TERINTEGRASI
}

\author{
Michael Ong ${ }^{1)}$, Dewi Ratnaningrum ${ }^{2)}$ \\ 1) Program Studi S1 Arsitektur, Fakultas Teknik, Universitas Tarumanagara, mmike209@gmail.com \\ 2) Program Studi S1 Arsitektur, Fakultas Teknik, Universitas Tarumanagara, dewir@ft.untar.ac.id
}

\begin{abstract}
Abstrak
Generasi Millennial adalah sebuah generasi yang sedang mendominasi di Indonesia, sebagai generasi yang keseluruhannya merupakan usia produktif dengan persentase terbesar dibandingkan dengan generasi usia lainnya. Sebagai generasi yang dominan, gaya hidup dan perilaku mereka layak menjadi perhatian. Dua hal yang dominan adalah: 1. Makanan, sebuah bagian besar dari gaya hidup mereka, terlihat dari pengeluaran Generasi Millennial untuk makanan, khususnya untuk makan di luar, merupakan pengeluaran terbesar mereka, dan; 2. Sedentary Lifestyle, $84 \%$ profesi penduduk Jakarta merupakan profesi yang tidak aktif, selain itu dengan kemajuan teknologi digital membuat aktivitas sehari-hari semakin menjadi kurang aktif. Kedua gaya hidup ini perlu menjadi perhatian, karena keduanya merupakan penyebab utama dari Obesitas, yaitu penyebab 4 dari 5 penyakit penyebab kematian tertinggi di Indonesia, serta diderita oleh $37.1 \%$ penduduk dewasa Jakarta. Sebagai upaya penyelesaian dari masalah ini, sebuah program dan fasilitas dirancang untuk menyelesaikan masalah ini secara preventif, yaitu melalui menumbuhkan kebiasaan gaya hidup sehat. Metode perancangan yang digunakan adalah tipologi. Secara fungi mengikuti trend wellness center, yaitu kesehatan tidak hanya melalui pengobatan, tetapi juga melalui gaya hidup sehat. Selain itu secara bentuk, yaitu menghasilkan bangunan yang melalui bentuknya mendorong gaya hidup sehat. Berdasarkan ini, bangunan yang dihasilkan adalah Integrated Health Facility, yaitu sebuah fasilitas kesehatan yang secara menyeluruh. Fokus utama dari fasilitas ini merupakan nutrisi (makanan) dan aktivitas fisik, dengan program utama yang ditawarkan dapat dikategorikan menjadi makanan, aktivitas fisik, klinik serta komunitas kesehatan. Tangga menjadi konsep utama dari bangunan, yaitu sebagai sirkulasi dan permainan split level, untuk mendorong aktivitas fisik secara pasif.
\end{abstract}

Kata kunci: Gaya Hidup; Generasi Millennial; Integrated Health; Obesitas; Preventif

\begin{abstract}
Millennials are currently the most prominent age demographic in Indonesia, a generation that has the highest number of people compared to other age groups that wholly consist of peope in productive age. As the prominent demographic group, their behaviour and lifestyle is an important trend that needs to be observed. Their 2 most dominant lifestlye are: 1. Food, a big part of their lifestyle, Millennials spend most of their money on food, especially on dining out, and; 2. Sedentary Lifestyle, $84 \%$ of Jakarta citizen's profession can be categorized as a job with passive physical activity, furthermore the advancement of digital technology has made daily activity less active. These things needs to be paid attention to, as both of them are the main cause of obesity, which itself is a major cause of 4 of 5 illness that caused death in Indonesia, and can be observed in $37.1 \%$ of adults in Jakarta. To mitigate this, a program is designed to solve this issue preventively, by instilling a healthy bevahiour in their daily life. The chosen design method is typology. Function-wise it is based on wellness center, which promotes health not only by medicine but also through building a healthy lifestyle. Shape-wise, is to design a building which passively promotes healthy lifestyle by its shape. Based on these, the proposed program is Integrated Health Facility, which is an integrative medicine based facility. The main focus of this program is diet nutrition and physical activiy, with the main program categorized as food, pyhsical activity, clinic, and health community. Stair is the main concept, used as the main circulation and split level design, to passively encourage physical activity.
\end{abstract}

Keywords: Integrated Health; Lifestyle; Millennial; Obesity; Preventive 


\section{PENDAHULUAN}

\section{Latar Belakang}

Generasi Millennial adalah sebuah generasi yang sedang mendominasi di Jakarta dan Indonesia. Berdasarkan proyeksi dari Badan Pusat Statistik untuk tahun 2010 - 2035, 34\% persen dari penduduk Indonesia pada tahun 2020 merupakan Generasi Millennial, sementara 27\% penduduk Jakarta pada tahun 2019 merupakan Generasi Millennial. Dengan jumlahnya yang mendominasi, serta dengan keseluruhannya merupakan usia produktif, bisa dilihat bahwa Generasi Millennial akan memiliki sebuah pengaruh yang besar dalam tren perilaku dan gaya hidup, yang akan berdampak pada tren kebutuhan. Sehingga perilaku dan gaya hidup dari Generasi Millennial menjadi sesuatu yang layak untuk diperhatikan.

Terdapat 2 gaya hidup dan perilaku Generasi Millennial yang dominan yang dipilih. Pertama adalah makanan. Berdasarkan infografik dari tim riset tirto.id, pengeluaran Generasi Millennial terbesar adalah untuk restoran $(23,8 \%)$ dan untuk bahan makanan $(21,7 \%)$. Secara persentase menghabiskan uang, Millennials $71,4 \%$ digunakan untuk makan di luar, dan 31,7\% untuk bahan makanan. Hal ini lebih besar bila dibandingkan dengan Baby Boomers, yang hanya $51,2 \%$ menghabiskan uang untuk makan di luar, dan 26,5\% untuk bahan makanan. Selain itu, berdasarkan infografik dari moneysmart.id, 23,3\% pengeluaran gaya hidup anak Jakarta digunakan untuk nongkrong di café. Hal ini menunjukkan bahwa makanan merupakan sebuah gaya hidup bagi Generasi Millennials, khususnya di Jakarta, yang dominan.

Selain makanan, Sedentary Lifestlye atau gaya hidup tidak aktif juga merupakan sebuah perilaku dominan Generasi Millennial. Hal ini dilihat berdasarkan profesi mereka. Berdasarkan data dari Pemda DKI Jakarta, pada tahun 2014, 84.1\% penduduk Jakarta memiliki profesi yang tidak aktif. Profesi-profesi ini adalah karyawan (25.67\%), pelajar/mahasiswa (22,8\%), mengurus rumah tangga $(19,2 \%)$, serta tidak/belum bekerja $(16,6 \%)$. Sebagai generasi yang sedang mendominasi berdasarkan jumlah, serta keseluruhannya merupakan usia produktif, tentunya sebagian besar dari Generasi Millennial akan termasuk dalam profesi-profesi ini. Selain itu, sebagai generasi yang disebut digital native, kemajuan teknologi digital adalah sesuatu yang dimanfaatkan dalam kegiatan mereka sehari-hari. Perkembangan teknologi digital, yang pada umumnya mempermudah kegiatan yang dilakukan sehari-hari, juga membuat gaya hidup semakin tidak aktif. Sehingga secara umum bisa dikatakan bahwa generasi ini memiliki gaya hidup yang tidak aktif.

Bila dilihat dari dua perilaku Generasi Millennial yang dominan ini, terdapat sebuah masalah yang didasari oleh 2 hal ini, yaitu Obesitas. Menurut National Health Service of the United Kingdom (2019), pada umumnya obesitas disebabkan oleh dua hal yaitu makan dalam jumlah yang berlebih serta pergerakan yang terlalu sedikit. Makan dalam jumlah yang terlalu banyak memiliki hubungan dengan perilaku Millennial yang pengeluaran terbesarnya adalah untuk makan, khususnya makan di luar. Sementara itu Sedentary Lifestyle sendiri merupakan bentuk dari pergerakan yang terlalu sedikit. Hal ini menunjukkan, bahwa berdasarkan gaya hidup mereka, Generasi Millennial memiliki resiko untuk terkena obesitas. Selain itu, berdasarkan data dari Kementerian Kesehatan, lebih dari seperempat penduduk dewasa di Indonesia mengalami obesitas, dengan Jakarta berada di peringkat pertama secara nasional, dengan $37,1 \%$ penduduk dewasanya mengalami obesitas. Dengan keseluruhan Generasi Millennial merupakan usia dewasa, tentunya akan memiliki kecenderungan yang lebih tinggi untuk mengalami obesitas. Kecenderungan untuk obesitas ini merupakan hal yang negatif. Menurut riset Mboi et al (2016), 4 dari 5 penyebab kematian tertinggi di Indonesia adalah penyakit arteri koroner, stroke, diabetes, TBC, serta sakit punggung dan pinggang. Kecuali TBC, keempat penyakit tersebut dapat disebabkan oleh obesitas. Sehingga terlihat bahwa obesitas merupakan masalah yang perlu diselesaikan. 


\section{Rumusan Masalah}

a. Apakah perilaku dan gaya hidup Generasi Millennial yang dominan, dan apakah masalah yang dihasilkan dari kedua hal tersebut?

b. Bagaimana menghasilkan fasilitas yang dapat mewadahi program untuk mengatasi masalah tersebut?

\section{Batasan Penelitian}

Subjek

Proyek

Lokasi Proyek

: Pekerja, khususnya Generasi Millennial

: Restoran, fitness center, klinik

: Kelurahan Kebon Sirih, Kecamatan Menteng, Jakarta Pusat

\section{Tujuan Penelitian}

Tujuan dari Integrated Health Facility adalah membangun sebuah fasilitas yang mewadahi aktivitas kesehatan yang terintegrasi, khususnya kesehatan fisik yang memiliki hubungan akan makanan dan aktivitas fisik, yaitu dari aspek makanan, aspek aktivitas fisik, dan aspek klinis serta komunitas. Fasilitas yang dihasilkan merupakan fasilitas yang mewadahi program yang mencegah masalah obesitas secara preventif, yaitu menggunakan aspek-aspek ini sebagai program untuk menghasilkan gaya hidup sehat.

\section{KAJIAN LITERATUR}

\section{Generasi Millennial}

Secara umum, Generasi Millennial bisa disimpulkan sebagai generasi yang lahir pada jangka tahun awal 1980 hingga akhir 1990. Hal ini disimpulkan berdasarkan Pew Research Center (2018), yang mendefinisikan Millennial sebagai generasi yang lahir pada 1981 - 1996; dan Carlson (2008) yang menyebut generasi ini sebagai generasi yang lair pada 1983- 2001.

\section{Kesehatan Terintegrasi/Integrated Health}

Fasilitas Kesehatan Terintegrasi, atau Integrated Health Facility, berasal dari kata Integrative Medicine dan Health. Integrative Medicine, menurut Andrew Weil Center for Integrative Medicine (2019), adalah sebuah pengobatan yang berorientasikan pada penyembuhan yang berdasarkan pada keseluruhan aspek seseorang, termasuk semua aspek gaya hidup. Sementara kata Health, menurut WHO (1946), adalah sebuah keadaan kesehatan secara fisik, mental, dan sosial, tidak hanya bebas dari penyakit. Berdasarkan dua definisi ini, Integrated Health Facility dapat diartikan sebagai fasilitas yang menjadi wadah untuk penyediaan kesehatan secara menyeluruh, baik fisik, mental, dan sosial, yang didasarkan pada keseluruhan aspek seseorang.

\section{Obesitas}

Obesitas dan kelebihan berat badan, berdasarkan definisi WHO (2018), adalah akumulasi lemak yang berlebihan dan abnormal yang dapat mempengaruhi kesehatan. Diukur menggunakan $\mathrm{BMI}$, dengan satuan $\mathrm{kg} / \mathrm{m} 2$. $\mathrm{BMI} \geq 25$ bagi orang dewasa akan termasuk kategori kelebihan berat badan, sementara $\mathrm{BMI} \geq 30$ merupakan kategori obesitas.

Menurut WHO (2018), penyebab dari obesitas dan kelebihan berat badan secara umum adalah: bertambahnya konsumsi makanan yang padat energi dan memiliki kadar lemak yang tinggi, serta berkurangnya aktivitas fisik dikarenakan bertambahnya sifat-sifat sedentary pada pekerjaan dan transportasi, serta bertambahnya urbanisasi. Sementara menurut NHS (2019), obesitas disebabkan oleh diet yang buruk (makan terlalu banyak, minum alkohol terlalu banyak, terlalu sering makan ke luar, minum minuman bergula terlalu banyak, comfort eating), kekurangan aktivitas fisik (terlalu banyak duduk saat bekerja, lebih banyak menggunakan mobil dibandingkan dengan berjalan kaki ataupun bersepeda, menggunakan gadget, serta jarang berolahraga), genetik, serta alasan medis lainnya.

Untuk penanganan obesitas, beberapa cara yang bisa dilakukan menurut WHO (2018) adalah: mengurangi energi yang didapatkan dari lemak dan gula, meningkatkan konsumsi buah, 
sayuran, dan legum, serta aktivitas fisik secara rutin (150 menit per minggu untuk orang dewasa). Sementara berdasarkan NHS (2019), beberapa cara yang dapat dilakukan adalah dengan diet sehat, melakukan pengecekan kalori makanan yang dikonsumsi, olahraga dengan intensitas moderat 150 menit per minggu (contoh: berjalan cepat, bersepeda, berenang, menari). Weight Loss Group, Exercise Prescription, melakukan aktivitas dengan elemen sosial, serta memecah waktu duduk dengan sesekali berdiri dan bergerak. Tidak hanya itu, menggunakan tangga juga dapat membantu dalam peningkatan kesehatan. Hasil riset oleh Rodney et al (2007) menunjukkan bahwa penggunaan tangga kurang dari 30 menit per minggu meningkatkan kesehatan kardiovaskular.

Mengenai penderita obesitas, menurut Houle (2013), pada negara berpendapatan rendah, orang dengan status sosial-ekonomi yang lebih tinggi memiliki kecenderungan yang lebih tinggi untuk terkena obesitas. Sebaliknya, pada negara berpenghasilan tinggi, orang dengan status sosial-ekonomi yang lebih tinggi memiliki kecenderungan yang lebih rendah untuk terkena obesitas. Hal ini mungkin disebabkan di negara berpenghasilan rendah, status sosial-ekonomi yang lebih tinggi menuju akan konsumsi makanan dengan kalori yang lebih tinggi dan menghindari aktivitas fisik yang lebih berat. Sementara pada negara berpenghasilan tinggi, status sosial-ekonomi yang lebih tinggi lebih cenderung untuk makan makanan yang lebih sehat dan rutin berolahraga.

\section{Tipologi Healthcare}

Konsep dan prinsip dari fasilitas healthcare mengalami perkembangan dan perubahan dari jaman ke jaman. Berdasarkan artikel Prasad (2012), perkembangannya dapat dirangkum sebagai berikut:

- Rumah sakit pada awalnya diletakan jauh dari kota.

- Berawal mula dari peradaban kuno. Memiliki ide bahwa sebuah rumah sakit sebagai sebuah mekanisme efektif untuk perawatan dan sebagai tempat untuk penyembuhan.

- Tipologi "paviliun" yang dikembangkan pada akhir abad ke-18 dan menjadi populer di pertengahan abad ke-19, yaitu ruangan-ruangan disusun pada blok-blok persegi panjang dengan lebar yang sempit, dihubungkan dengan koridor-koridor. Bentuk ini digunakan untuk memberikan ventilasi maksimum untuk meningkatkan kesehatan dan penyembuhan.

- Pada abad ke 20 rumah sakit pada umumnya mengikuti prinsip functionalism, berfokus pada efisiensi akomodasi sehingga mengorbankan bentuk yang bermakna serta tempat yang hidup.

- 4 elemen yang menjadi dasar tipologi rumah sakit adalah: In-patient ward, outpatient dan diagnostic departments, operating theatres, serta servis dan sirkulasi.

- Patient centred design menjadi perhatian pada pertengahan abad ke-20, dengan eksplorasi mengenai pengalaman sensori yang lebih baik bagi manusia, seperti kualitas ruang, pencahayaan, akustik dan finishing, serta bagaimana mengurangi stress dengan membuat bangunan menyenangkan untuk dikunjungi dan navigasi dalam bangunan yang lebih mudah.

- Dimulai di rumah sakit yang berada di Inggris pada abad ke-18 dan ke-19, rumah sakit memiliki kontinuitas fungsi dengan urban public realm, dengan membuat urban space yang bisa digunakan oleh publik. Hal ini membuat public place di kota tersebut diuntungkan dengan adanya rumah sakit, juga mempermudah pemilihan tapak bagi rumah sakit.

\section{Lingkungan Healthcare}

Menurut Kopec (2012) pada bukunya Environmental Psychology for Design, beberapa hal yang perlu diperhatikan pada saat merancangan fasilitas healthcare adalah:

a. Skala

- Penggunaan skala manusia, untuk menciptakan kesan "homey"

- Menghindari fasad bangunan yang terlalu masif. Berikan kesan kehadiran manusia melalui landscaping. 


\section{b. View}

- Menurut Sherman et al (2005), taman dan area hijau membantu penyembuhan pasien.

- Stress dapat dikurangi dengan pemandangan alam, seperti taman.

- Penggunaan warna-warna yang tipikal digunakan di rumah atau hotel

- Penggunaan berbagai jenis pengalihan seperti televisi, bahan bacaan, dan lainlainya.

\section{Fitness Center dan Wellness Center}

Berdasarkan Diedrich (2005), fitness center berupa fasilitas latihan fisik. Dapat berupa bagian dari: Commercial Venture, Private Club, amenitas dari resort, fasilitas hotel, rumah sakit serta perawatan terapi, fasilitas rekreasional, spa, dan komunitas gereja. Fasilitas yang berada dalam wellness center, antara lain: Gym, studio untuk Group Exercise dan latihan aerobik, gymnasium (multisport area), kolam renang, dan jogging track.

Berdasarkan artikel yang ditulis oleh Mckenna (2013), secara umum misi dari wellness center adalah untuk mengembangkan health and well-being. Wellness center merupakan hasil dari pendekatan yang lebih menyatu antara kesehatan (health) dan kebugaran (wellness). Sebagai contoh: The Student Wellness and Recreation Center di Georgia College and State University menggabungkan lapangan basket, treadmill, dan area lounge dengan layanan konseling kesehatan mahasiswa; University of Colorado Denver's Anschutz Health and Wellness Center dirancang untuk menumbuhkan kebiasaan sustainable, gaya hidup sehat, dan pencegahan penyakit, dengan program menggabungkan fitness center, wellness clinic, laboratorium riset, vegetable and herb garden, healthy bistro, research and educational grocery lab, classrooms, dan meeting room.

\section{METODE}

\section{Metode Penelitian}
a. Subjek Penelitian
: Generasi Millennial, pekerja kantoran
b. Objek Penelitian
: Jalan Menteng Raya, Kebon Sirih
c. Unsur yang diteliti
: gaya hidup dan perilaku Generasi Millennial, obesitas, Kondisi tapak Jalan Menteng Raya, Kebon Sirih
d. Pengumpulan data
: Observasi, studi pustaka
e. Sumber data
: Primer (observasi tapak), sekunder (literatur, peraturan pemerintah)

Metode penelitian yang digunakan adalah penelitian deskriptif. Penelitian deskriptif, menurut Suryana (2010), adalah metode yang digunakan untuk mencari unsur-unsur, ciri-ciri, sifat-sifat suatu fenomena. Dimulai dengan mengumpulkan data, menganalisis data, lalu diinterpretasikan. Pada penelitian ini, unsur-unsur dari Generasi Millennial, seperti gaya hidup dan perilakunya, serta literatur tentang obesitas, dan keadaan tapak, dianalisis, untuk menghasilkan Integrated Health Facility.

\section{Metode Perancangan}

Metode perancangan yang digunakan adalah tipologi. Menurut Tjahjono (2000), Kajian Tipologi adalah mengamati unsur-unsur yang membentuk sebuah bangunan. Unsur-unsur ini dipelajari untuk mengerti bagaimana unsur-unsur tersebut disusun oleh penyusunnya. Hal ini dilakukan agar prinsip penyusunan tersebut dapat dilakukan dapat dimanfaatkan sebagai contoh penyelesaian bangunan sejenis. Di dalam tipologi terdapat tipologi ruang kegiatan. Berdasarkan Tjahjono (2000), dalam menganalisis ruang gerak, tipe adalah kegiatan yang mendasar, sementara model adalah nama ruang tersebut. Pengembangan tipe dibandingkan dengan model, dapat melihat peluang lain yang tidak terikat dengan pengalaman yang pernah 
dialaminya, dapat mengembangkan dari yang mendasar ke berbagai wujud batas ruang.

Dalam proyek ini, tipologi dikaji melalui beberapa hal, yaitu:

a. Secara bentuk bangunan pada umumnya, yaitu kategori dan klasifikasi dari massing, denah, dan tampak. Melihat dan mengembangkan berdasarkan perkembangan prototipe dan stereotipe healthcare dan fitness center

b. Fungsi bangunan, yaitu tidak hanya fungsi kesehatan saja tetapi juga memasukan unsur makanan, aktivitas fisik, dan komunitas.

c. Tipologi ruang kegiatan, dengan masuknya digitalisasi ke dalam beberapa fungi, bentuk dari ruangan tersebut akan mengalami perbedaan dengan stereotipe ruangan aktivitas tersebut

d. Sirkulasi dalam bangunan, yaitu dengan penggunaan tangga sebagai sirkulasi utama serta permainan split level. Hal ini berdasarkan diagram hubungan tipe Yoshiharu Tsukamoto dan Momoyo Kajima, menghasilkan interaksi tipe -> model -> perilaku. Interaksi ini digunakan untuk mengendalikan massa dalam perancangan ruang publik.

\section{DISKUSI DAN HASIL}

\section{Program}

Berasal dari penggabungan kata Integrative Medicine dan Health. Integrated Health Facility merupakan sebuah fasilitas kesehatan di mana kesehatan tersebut didasari oleh aspek-aspek gaya hidup, tidak hanya secara klinis saja.

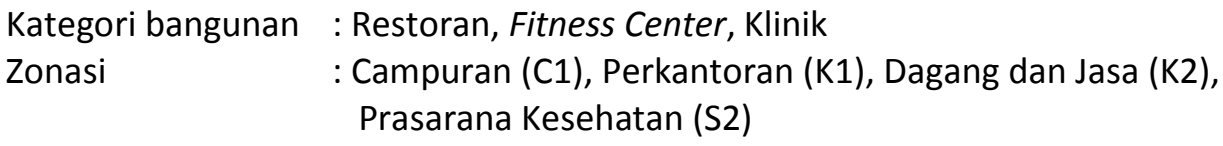

Usulan program didasarkan oleh 2 gaya hidup dan perilaku Generasi Millennial yang paling dominan, yaitu makanan dan sedentary lifestyle, yang berpotensi mengakibatkan obesitas. Sifat program lebih ke arah preventif dan rehabilitatif, dengan alasan program-program yang ditawarkan bersifat gaya hidup, sehingga bisa menjadi bagian dari kehidupan Generasi Millennial sehari-hari, untuk mendorong gaya hidup yang sehat.

Sasaran utama dari program ini adalah golongan ekonomi menengah ke atas, yaitu orangorang yang sudah bekerja, khususnya Generasi Millennial. Hal ini didasari oleh 2 hal, yaitu: 1. Menurut Saussier (2018), Generasi Millennial menyukai gaya hidup seputar "fun, health, and leisure", menunjukkan bahwa bangunan yang mencampurkan gaya hidup dengan kesehatan akan memiliki target utama Generasi Millennial; 2. Menurut Houle (2013), pada negara berkembang, masyarakat dengan kemampuan ekonomi menengah ke atas memiliki risiko yang lebih tinggi untuk menjadi obesitas. Sehingga sasaran utama adalah warga yang sudah berpenghasilan, karena akan berada di tingkat sosial ekonomi yang lebih tinggi. Selain itu, warga yang sudah berpenghasilan juga dapat berinvestasi untuk kesehatannya.

Program-program utama bangunan memiliki konsep digitalisasi, sehingga mempercepat proses yang dibutuhkan serta mempermudah akses, sehingga aktivitas tersebut dapat diselipkan pada kegiatan sehari-hari. Semua program pada bangunan disatukan melalui satu aplikasi, sehingga keseluruhan data dari makanan, aktivitas fisik, serta kesehatan bisa dipantau secara terintegrasi dan bisa saling dihubungkan untuk menghasilkan gaya hidup sehat yang optimal. 


\section{PROGRAM}
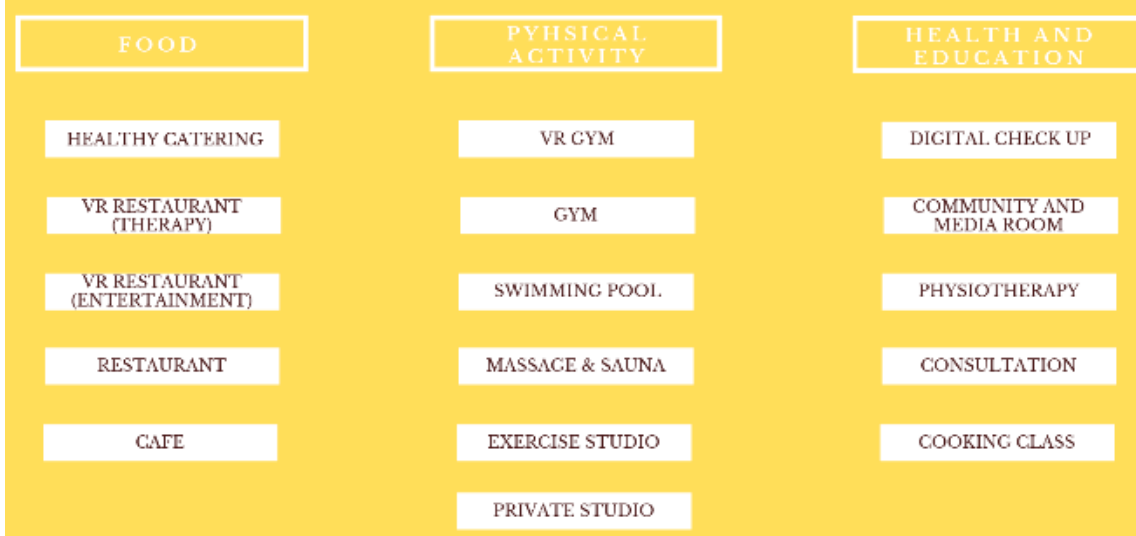

DIGITAL. CHECK UP

COMMUNITY AND

PHYSIOTHERAPY

CONSULTATION

COOKING CLASS

PRIVATE STUDIO

Gambar 1. Diagram Program Utama Bangunan

Sumber: Penulis, 2019

Program dibagi menjadi 3 Kelompok besar, yaitu:

a. Food Area: merupakan program-program yang fungi utamanya berhubungan dengan jualbeli makanan.

b. Physical Activity: merupakan program-program yang fungsi utamanya berhubungan dengan aktivitas fisik

c. Health and Community: merupakan program-program yang fungsi utamanya adalah yang berhubungan dengan konsultasi, pengecekan, dan rehabilitasi kesehatan, serta ruangruang untuk aktivitas komunitas yang berhubungan dengan kesehatan.

Pemilihan kelompok program ini didasari dari 3 cara mengatasi obesitas, yaitu diet sehat (Food Area), aktivitas fisik (Physical Activity), serta Weight Loss Group dan Exercise Prescription (Health and Community).

\section{Lokasi Site}

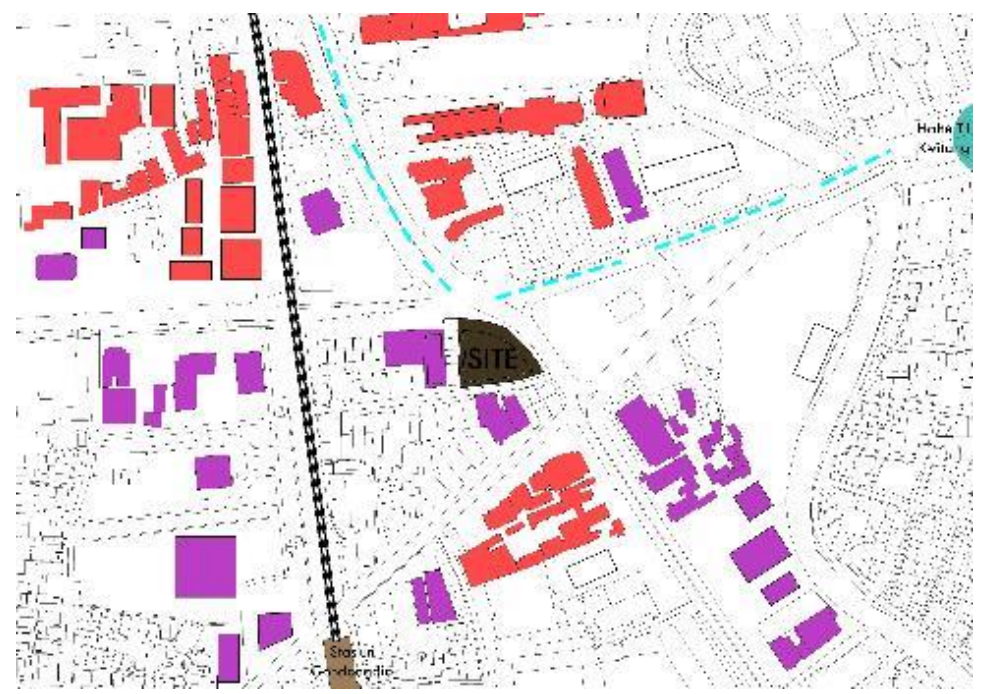

Gambar 2. Lokasi Site

Sumber: Penulis, 2019

Site berada di Jalan Menteng Raya, Kelurahan Kebon Sirih, Kecamatan Menteng, Jakarta Pusat. Site dipilih karena berada di tengah-tengah daerah perkantoran, yaitu perkantoran komersil (warna ungu pada gambar) dan kantor pemerintahan (warna merah pada gambar), 
serta lokasinya dekat dengan transportasi publik. Pemilihan site yang berdekatan dengan daerah perkantoran didasari oleh orang pekerja kantoran, cenderung akan termasuk dalam status ekonomi menengah ke atas, sehingga akan lebih beresiko untuk mengalami obesitas. Hal ini menyesuaikan dengan pernyataan Houle (2013), yaitu pada negara berkembang, orang dengan status sosial-ekonomi yang lebih tinggi memiliki kecenderungan yang lebih tinggi untuk terkena obesitas. Selain itu, site berada di dekat kantor dan berdekatan dengan transportasi publik, untuk memicu calon pengguna untuk berjalan kaki. Sesuai dengan konsep bangunan yang hendak menyelipkan aktivitas sehat dalam kegiatan sehari-hari, bangunan dapat diakses dalam radius berjalan kaki, sebagai perhentian dari dan menuju transportasi publik saat datang dan pulang dari bekerja, serta mudah diakses pada waktu istirahat atau waktu senggang di kantor.

\section{Konsep Bangunan}

Tipologi Bentuk

TIPOLOGI HEALTHCARE- WELLNESS CENTER

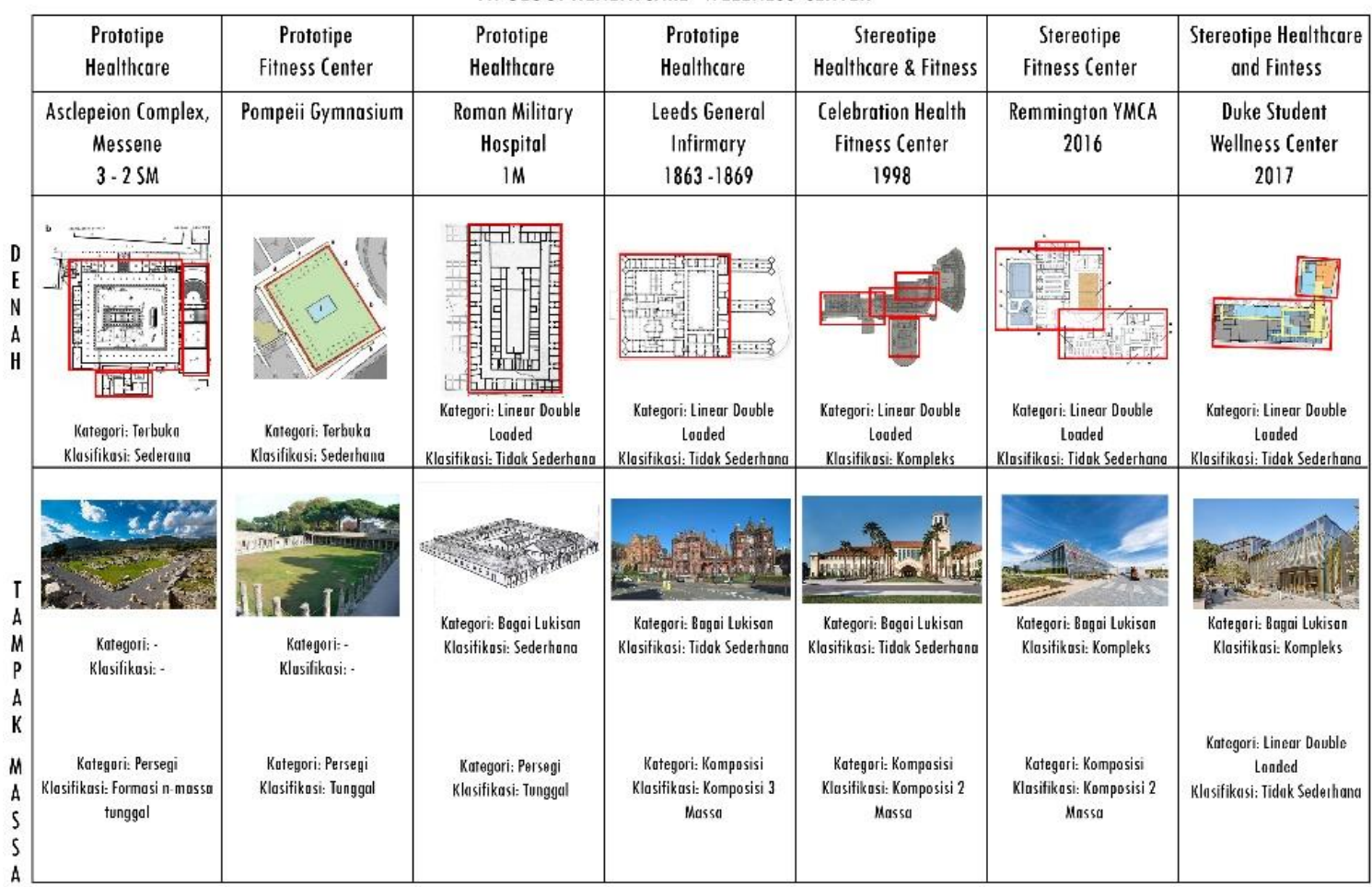

Gambar 3. Studi Tipologi Healthcare - Wellness Center

Sumber: Penulis, 2019

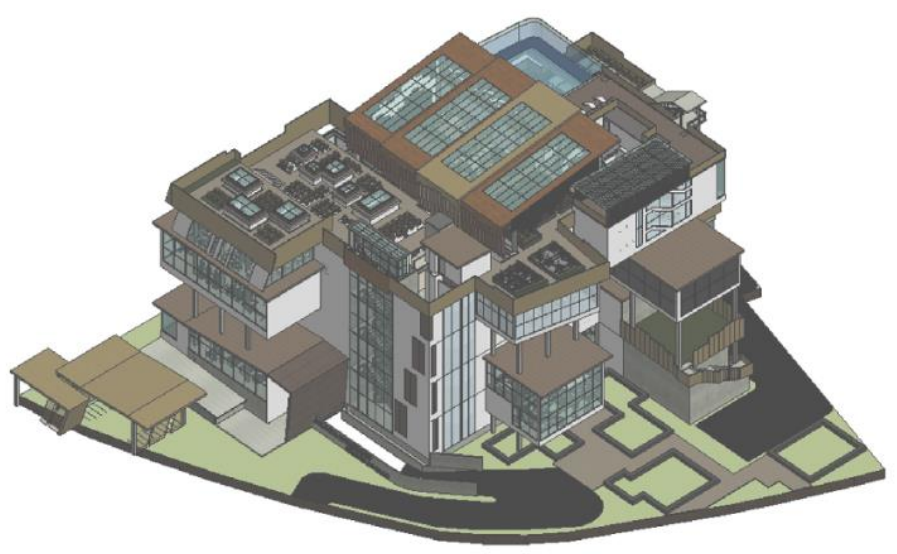

Gambar 4. 3D Bangunan

Sumber: Penulis, 2019 
Bentuk dasar bangunan, persegi, diambil berdasarkan studi tipologi prototipe dan stereotipe bentuk denah healthcare dan fitness center. Akan tetapi, untuk pengolahan massing dan tampak menjadi berbeda, yaitu merupakan komposisi n-massa secara volumetrik. Hal ini untuk menciptakan kontras dengan fasilitas-fasilitas yang sebelumnya, sehingga secara penampilan terlihat sebagai healthcare dan fitness center yang baru, tetapi secara fungsional tetap sesuai dengan kebutuhan program di dalamnya.

\section{Tipologi Ruangan}
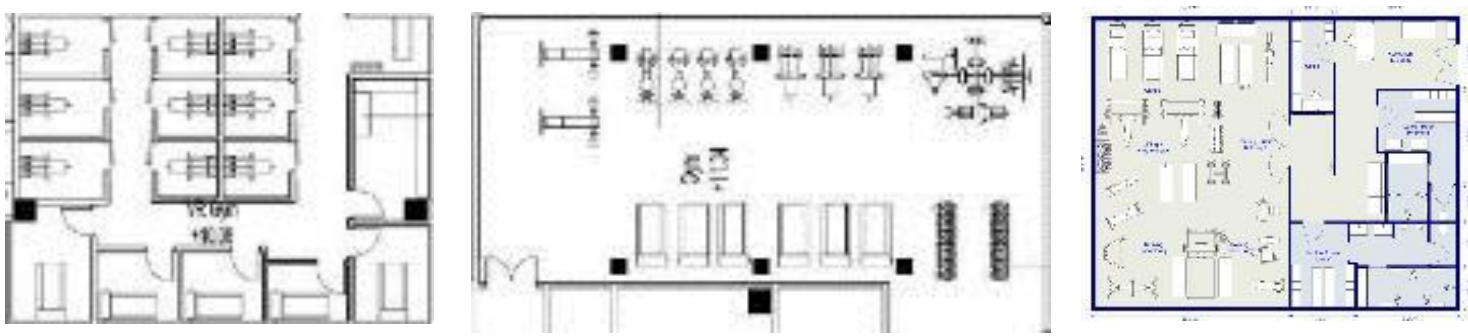

Perbedaan VR Gym dengan Gym Konvensional

Gambar 5 VR Gym, Gym, Denah Gym pada umumnya Sumber: Dokumentasi Pribadi, www.roomsketcher.com/floor-plans/gym-layout/

Terdapat perbedaan susunan ruang antara VR Gym dan Gym normal. VR Gym berupa sebuah ruang yang terbagi menjadi bilik-bilik personal, sementara Gym normal berupa sebuah open plan. Hal ini berdasarkan kebutuhan, yaitu pada VR Gym, aktivitas olahraga dilakukan dengan permainan $V R$ yang membutuhkan immersion, sehingga dibutuhkan bilik-bilik masing-masing agar kondisi dalam ruang dapat disesuaikan dengan kebutuhan pengguna. Sementara pada Gym biasa, tidak ada alat-alat yang memerlukan kebutuhan khusus sehingga sebuah open plan tidak menjadi suatu gangguan. Selain itu, pada gym biasa, dengan open plan bisa membuat adanya interaksi dengan pengguna lainnya, sesuatu hal yang tidak dilakukan dalam VR Gym karena masing-masing user berada di dalam game VRnya.

\section{Perbedaan Digital Check Up dengan Laboratorium Konvensional}
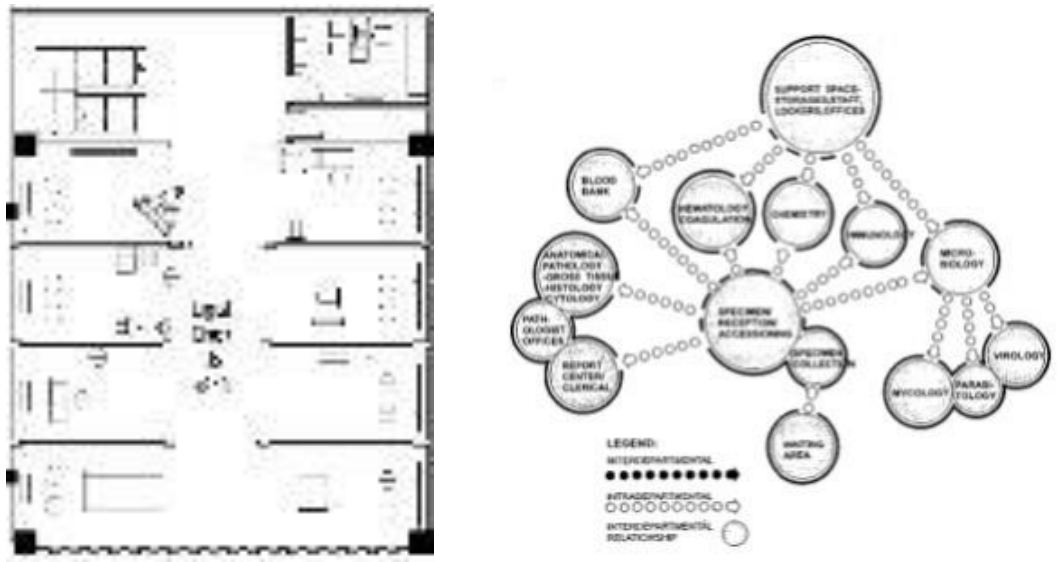

Gambar 6. Digital Check Up dan Alur Laboratorium Konvensional Sumber: Sumber: Penulis, 2019; Kliment et al (2008)

Terdapat perbedaan susunan ruang antara Digital Check Up dengan laboratorium konvensional. Pada laboratorium konvensional, peran pasien hanya sampai bagian penerimaan saja, sementara pada sisa tahap pengecekannya dilakukan secara back of house. Sementara 
pada Digital Check Up, semua proses pengecekan dilakukan secara langsung, sehingga pasien bisa mengikuti proses pengecekan dari awal hingga akhir, dan bisa mendapatkan penjelasan langsung dari dokter, sehingga proses berjalan secara lebih personal.

\section{Perbedaan VR Restaurant dengan Restoran}

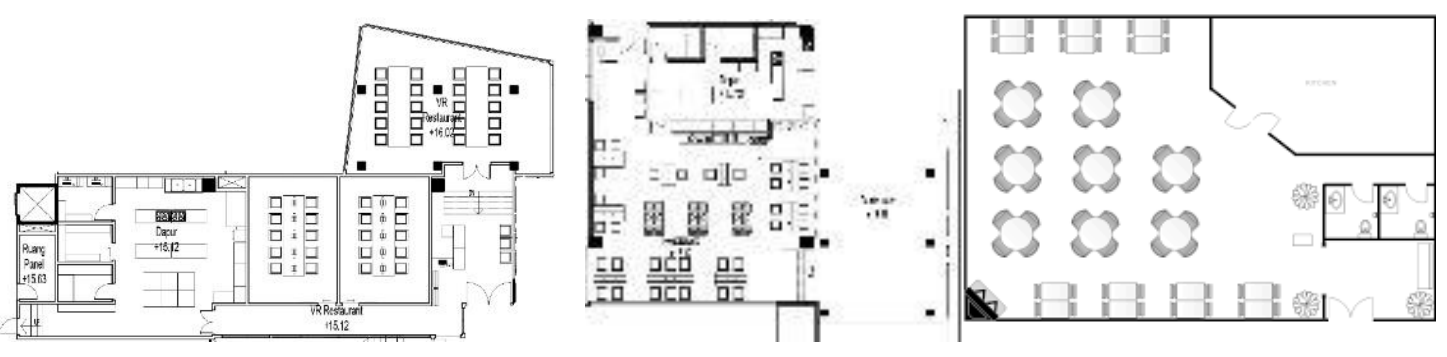

Gambar 7 VR Restaurant, Restoran, Denah Restoran pada umumnya Sumber: Dokumentasi Pribadi, https://www.smartdraw.com/restaurant-floorplan/examples/restaurant-layout/

Terdapat perbedaan susunan ruang $V R$ Restaurant dan restoran biasa. Restoran biasa mengikuti layout restoran pada umumnya, yaitu open plan. Sementara itu, untuk VR Restaurant, karena membutuhkan immersion $V R$ dalam pengalaman diningnya, dibagi menjadi per ruang-ruang.

\section{Tangga dan Split Level}

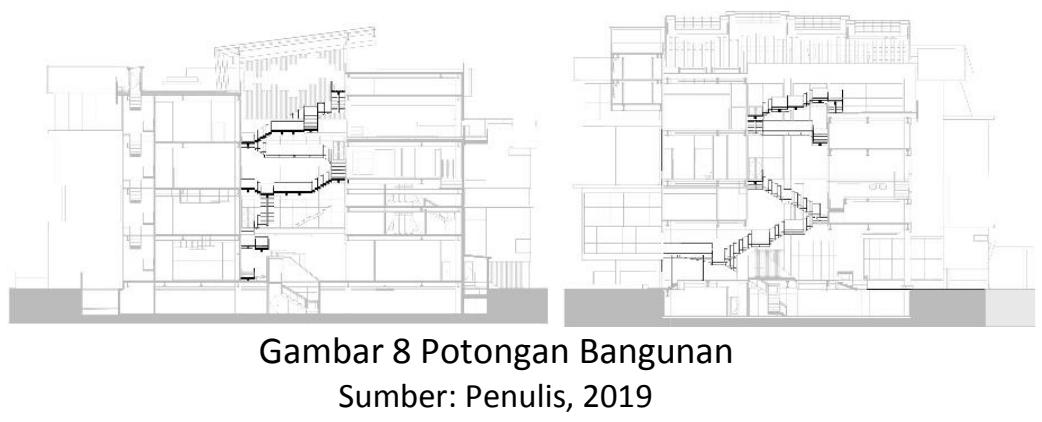

Tema dari bangunan ini adalah tangga, sehingga sirkulasi utama dari bangunan ini berupa tangga. Berada di void tengah, tangga ini menghubungkan Lantai 1 hingga Lantai Rooftop, serta lantai-lantai split level yang berada di void. Tangga dibuat sebagai sirkulasi utama sebagai unsur kesehatan secara pasif, didasari oleh hasil riset Rodney et al (2007) yang menunjukkan bahwa aktivitas naik tangga berfungsi meningkatkan kesehatan kardiovaskular. Lebar tangga 1,5 m, tidak terlalu lebar, agar pada saat ramai meningkatkan kecepatan jalan, meningkatkan tingkat aktivitas fisik pada saat di sirkulasi. Hal ini berdasarkan oleh riset Frohnwieser et al (2013), yaitu pada sirkulasi yang sempit, kecepatan berjalan akan meningkat.

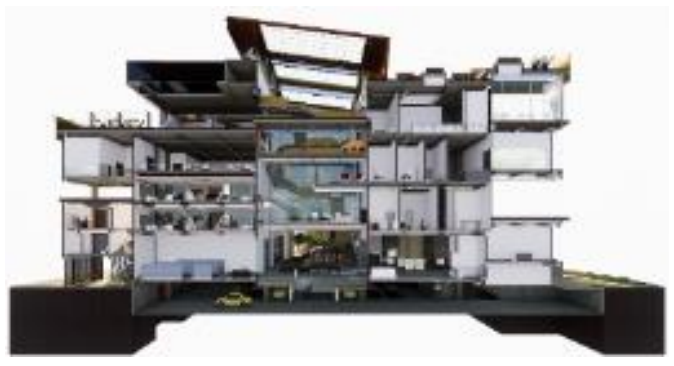

Gambar 9 Potongan Perspektif

Sumber: Penulis, 2019 
Tidak hanya melalui sirkulasi utama, ruang-ruang pada bangunan juga disusun dengan prinsip split level. Sehingga tidak hanya sirkulasi utama saja yang mendapatkan manfaat positif dari menggunakan tangga, tetapi manfaat positif dari penggunaan tangga juga masuk ke penggunaan tiap-tiap ruangan.

\section{Hasil Bangunan}

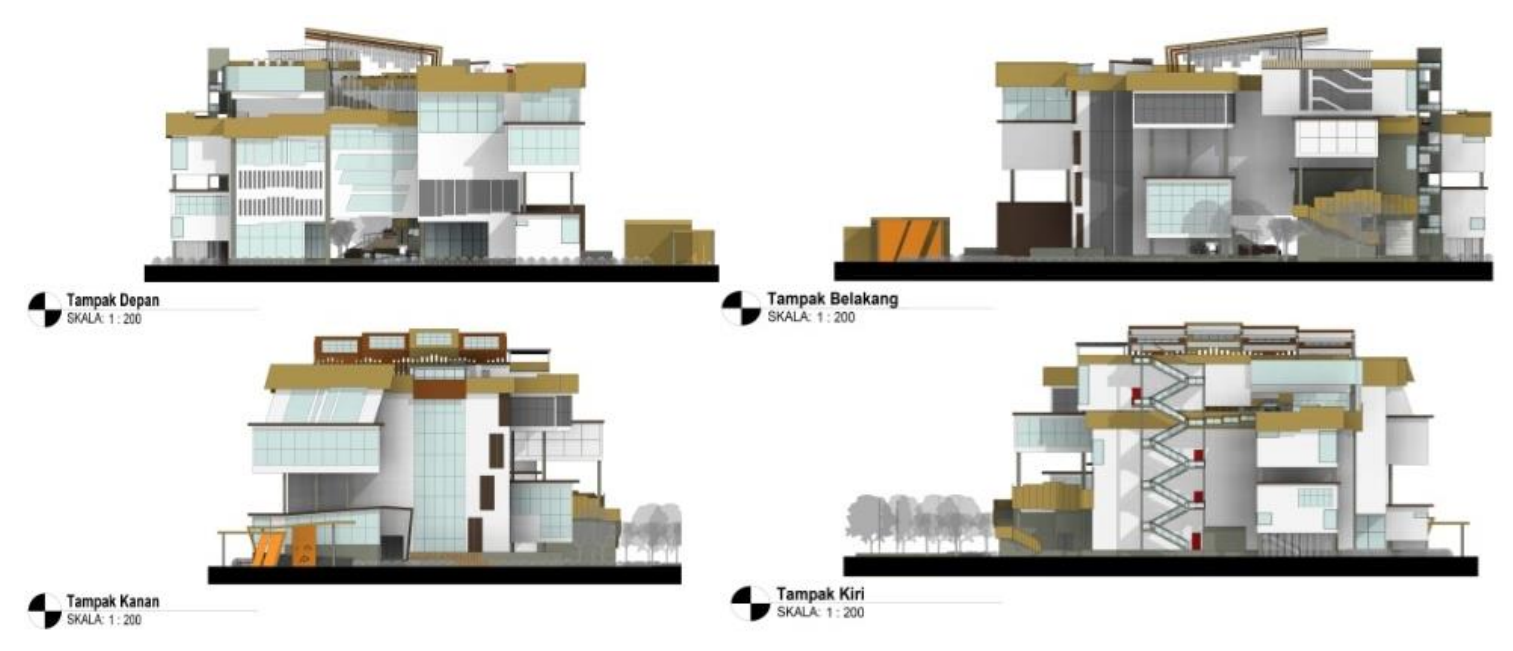

Gambar 10. Fasad Bangunan (4 Sisi)

Sumber: Penulis, 2019

Mengikuti tema bangunan, fasad juga memiliki unsur tangga. Unsur tangga pada fasad ini diterjemahkan menjadi permainan naik turun, sehingga pada keempat fasad, baik pola massing, bentuk jendela, maupun second skin dan dinding parapet semuanya mengikuti konsep ini.

Agar kesan bangunan tidak masif dan institusional, mengikuti pendapat Kopec (2012) tentang skala dan view, massing merupakan pecahan-pecahan bentuk serta terdapat permainan majumundur dan masif-transparan, untuk menghindari kesan satu massa yang masif. Selain itu, pemilihan warna juga memiliki warna cerah yang berbeda-beda, untuk menampilkan kesan homey. Adanya roof garden serta taman di fasad, juga didasari pendapat ini, yaitu penghijauan untuk mengurangi stress pengunjung serta membantu proses penyembuhan.

Zoning bangunan dibagi per lantai secara vertikal. Lantai Basement digunakan sebagai tempat parkir dan servis. Lantai 1, ditargetkan sebagai daerah publik serta untuk fungsi-fungsi yang membutuhkan untuk dilewati oleh pengunjung, memiliki zoning campuran antara publik, food area, serta health and community. Lantai 2 adalah untuk zona health and community, dengan alasan kebutuhan untuk kemudahan akses bagi fungsi health dan agar fungsi community menjadi lebih terekspose. Food area, sebagai fungsi yang paling sering dicari, diletakkan di paling atas, sehingga berfungsi seperti anchor pada shopping centre, sehingga paling berpotensi mendorong penggunaan tangga. Physical activity diletakkan ditengah-tengah, menyeimbangkan antara fungsi yang cukup populer serta karena sifatnya yang sudah berupa aktivitas fisik sehingga penggunaan tangga sebagai sirkulasi utama untuk pendorongan aktivitas fisik tidak diperlukan yang paling maksimal. 


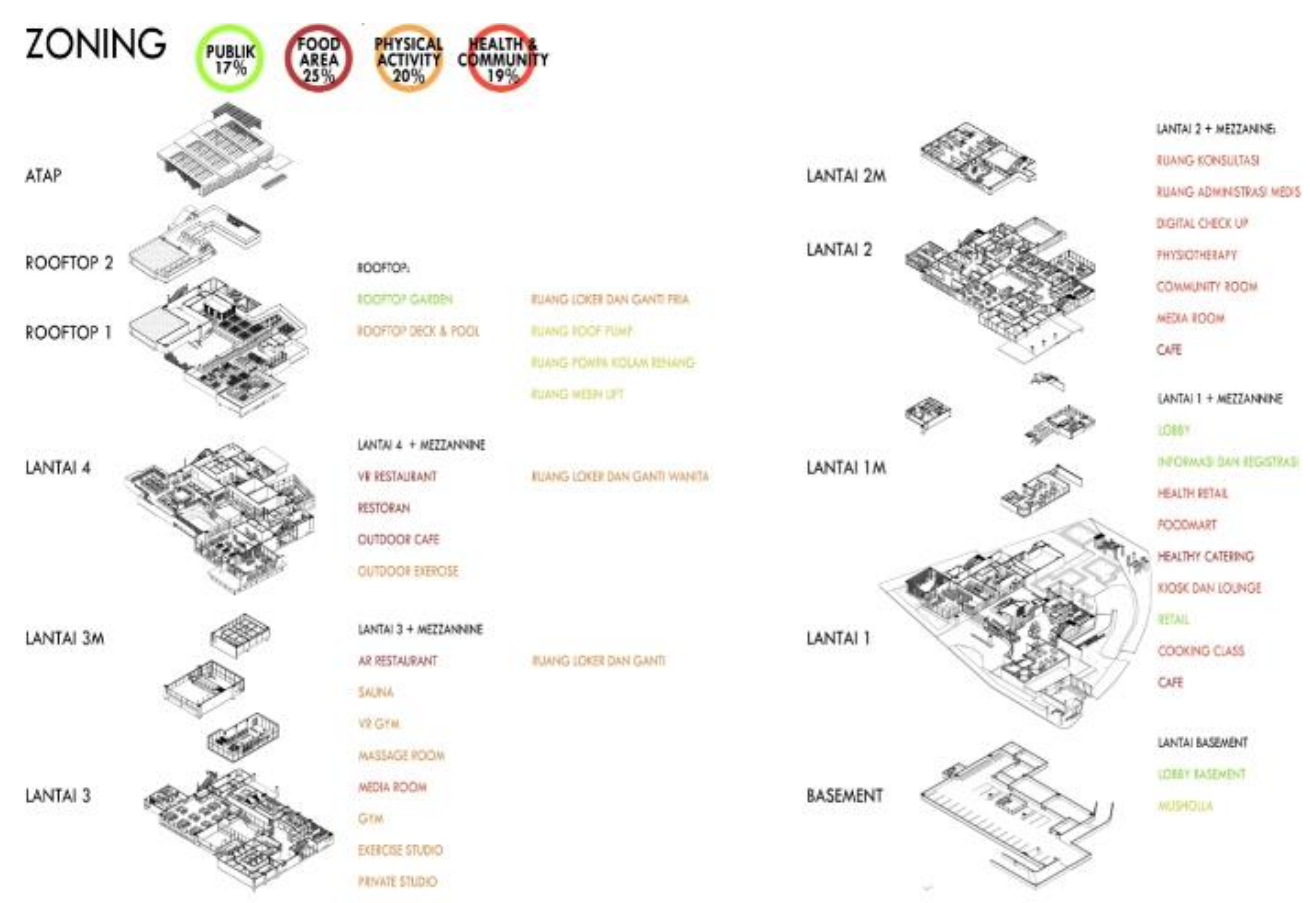

Gambar 11. Zoning dan Denah Axonometri Sumber: Penulis, 2019

\section{KESIMPULAN DAN SARAN}

\section{Kesimpulan}

a. Terdapat 2 perilaku dan gaya hidup Generasi Millennial yang cukup dominan, yaitu menyangkut tentang makanan dan sedentary lifestyle. Kedua hal ini dapat menyebabkan obesitas bagi Generasi Millennial, karena merupakan penyebab utama dari obesitas.

b. Untuk menghasilkan fasilitas yang dapat mewadahi pengatasan atas masalah obesitas untuk Generasi Millennial ini, diperlukan penggabungan dari beberapa aspek. Untuk menghasilkan program yang efektif, program tersebut merupakan gabungan dari perilaku dan gaya hidup Generasi Millennial, serta berdasarkan dari cara-cara pengatasan obesitas. Selain secara program, penyelesaian untuk obesitas juga dimasukkan ke dalam bentuk bangunan itu sendiri, yaitu melalui pembentukan perilaku. Pembentukan perilaku ini datang dari perancangan sebuah tipe, yang menghasilkan sebuah model, yang mengatur perilaku yang diinginkan. Pada kasus ini adalah pemasukan tangga sebagai sirkulasi utama bangunan dan split level, dengan perilaku yang diinginkan adalah peningkatan aktivitas fisik pada keseharian, yang dilakukan melalui penggunaan tangga.

\section{Saran}

Dilihat bahwa dua perilaku dan gaya hidup Generasi Millennial yang dominan merupakan penyebab utama dari obesitas, serta dengan dominannya Generasi Millennial pada zaman sekarang, dibutuhkan fasilitas-fasilitas yang menggabungkan aspek gaya hidup dengan prevensi obesitas, sehingga mengurangi resiko dan Generasi Millennial yang mengalami obesitas.

\section{REFERENSI}

Carlson, E. (2008). The Lucky Few: Between the Greatest Generation and the Baby Boom.Springer Debora, Y. (2017). Ke Mana Mengalirnya Uang Para Millennial?. Diperoleh dari https://tirto.id/ke-mana-mengalirnya-uang-para-milenial-cv76. 
Dinas Kependudukan dan Catatan Sipil. (2018). Data Jumlah Penduduk Berdasarkan Kelompok Usia per Kelurahan. Diperoleh dari http://data.jakarta.go.id/dataset/data-jumlah-pendudukprovinsi-dki-jakarta-berdasarkan-kelompok-usia-per-kelurahan/resource/3c672c08-a94c4e57-8ce9-67e3d357d1d0.

Fry, R. (2018). Millennials projected to overtake Baby Boomers as America's largest generation. Diperoleh dari: https://web.archive.org/web/20190309173020/http://www.pewresearch.org/facttank/2018/03/01/millennials-overtake-baby-boomers/

Frohnwieser, A., Hopf, R., \& Oberzaucher, E. (2013). Human walking behavior: the effect of pedestrian flow and personal space invasions on walking speed and direction. Human Ethology Bulletin, 28(3), 20-28.

Hidayah, A. (2018). Buat Ngopi Habiskan Sejuta, Ini Potret Gaya Hidup Millennial Jakarta. Diperoleh dari https://www.moneysmart.id/konsumtif-dan-boros-jadi-gaya-hidup-milenialjakarta/.

Houle, B. (2013). How Obesity Relates to Socioeconomic Status. Diperoleh dari https://www.prb.org/obesity-socioeconomic-status/

Katadata. (2016). 20 Profesi Warga Jakarta, Apa yang Dominan?. Diperoleh dari https://databoks.katadata.co.id/datapublish/2016/09/08/26-persen-warga-jakarta-bekerjasebagai-karyawan.

Kennedy, R. A., Boreham, C. A., Murphy, M. H., Young, I. S., \& Mutrie, N. (2007). Evaluating the effects of a low volume stairclimbing programme on measures of health-related fitness in sedentary office workers. Journal of sports science \& medicine, 6(4), 448.

Kobus, R. L., Skaggs, R. L., Bobrow, M., Kliment, S. A., Thomas, J., \& Payette, T. M. (2008). Building Type Basics for Healthcare Facilities (Vol. 13). John Wiley \& Sons.

Kopec, D. A. (2006). Environmental Psychology for Design. New York: Fairchild.

Lau, D. C., Douketis, J. D., Morrison, K. M., Hramiak, I. M., Sharma, A. M., \& Ur, E. (2007). 2006 Mboi, N., Surbakti, I. M., Trihandini, I., Elyazar, I., Smith, K. H., Ali, P. B., \& Glenn, S. D. (2018). On the road to universal health care in Indonesia, 1990-2016: a systematic analysis for the Global Burden of Disease Study 2016. The Lancet, 392(10147), 581-591.

Mckenna, C. (2013). Welcome to the Wellness Center: A New Breed of Recreation Design. Diperoleh dari: https://www.archdaily.com/421042/the-wellness-center-a-new-breed-ofrecreation-design

Nandini, W. (2018). 1 dari 4 Penduduk Dewasa Mengalami Obesitas. Diperoleh dari https://katadata.co.id/infografik/2018/04/05/1-dari-4-penduduk-dewasa-mengalamiobesitas.

National Health Service.of the United Kingdom. (2019). Obesity. Diperoleh dari https://www.nhs.uk/conditions/obesity/

Prasad, S. (2012). Typology: Hospital. Diperoleh dari https://www.architecturalreview.com/essays/typology/typology-hospitals/8629443.article

Richard J. Diedrich, \& Stephen A. Kliment. (2005). Building Type Basics for Recreational Facilities. John Wiley \& Sons.

Saussier, J. (2018). Millennials Supertrend: Investing in Fun, Health, and Leisure. Diperoleh dari https://www.credit-suisse.com/corporate/en/articles/news-and-expertise/millennialssupertrend-investing-in-fun-health-and-leisure-201809.html.

Sutanto, A., dan Andani, L.(2018).Dear Millennials, Dialogue Between Type and Behaviour. Jakarta.

Tate, D. F., Jeffery, R. W., Sherwood, N. E., \& Wing, R. R. (2007). Long-term weight losses associated with prescription of higher physical activity goals. Are higher levels of physical activity protective against weight regain?. The American journal of clinical nutrition, 85(4), 954-959. 
The University of Arizona: Andrew Weil Center for Integrative Medicine. (2019). What is Integrative Medicine. Diperoleh dari https://integrativemedicine.arizona.edu/about/definition.html.

Tjahjono, G. (2000). Metode Perancangan Suatu Pengantar Untuk Arsitek dan Perancang. Jakarta: Universitas Indonesia.

World Health Organization. (2018). Obesity and overweight. Diperoleh dari https://www.who.int/en/news-room/fact-sheets/detail/obesity-and-overweight 